\title{
Clinical efficacy of calcitonin compared to diclofenac sodium in chronic nonspecific low back pain with type I Modic changes: a retrospective study
}

This article was published in the following Dove Press journal: Journal of Pain Research

Jiaming Zhou ${ }^{1,2}$

Tengshuai $\mathrm{Li}^{\prime}$

Liandong $\mathrm{Li}^{1}$

Yuan Xue'

'Department of Orthopaedics Surgery, Tianjin Medical University General Hospital,Tianjin, People's Republic of China; ${ }^{2}$ Graduate School, Tianjin Medical University, Tianjin, People's Republic of China
Correspondence: Yuan Xue Department of Orthopaedics Surgery, Tianjin Medical University General Hospital, No. I54 Anshan Road, Heping District, Tianjin 300052, People's Republic of China

Tel +8622 608I 4688

$\mathrm{Fax}+862227219052$

Email xueyuanzyy@163.com
Background: The objective of this study was to compare the efficacy of calcitonin with diclofenac sodium in the treatment of patients with nonspecific low back pain (LBP) and type I Modic changes (MC1).

Patients and methods: The study was a retrospective observational study with 109 patients who had nonspecific LBP and MC1 that appeared as bone marrow lesions on magnetic resonance imaging (MRI). Between October 2013 and March 2016, 62 patients were injected intramuscularly with calcitonin 50 IU once daily and 47 patients were treated with diclofenac $75 \mathrm{mg}$ once per day for 4 weeks for the treatment of LBP associated with MC1 on MRI. Visual analog scale (VAS) (0-10) and Oswestry Disability Index (ODI) (0-100) questionnaires were acquired from clinical records to evaluate LBP perception and degree of disability. Imaging data were also collected before and after treatment.

Results: Significant improvements were found in VAS and ODI at posttreatment compared with baseline in both groups $(P<0.05)$. Meanwhile, there was a significant difference between calcitonin group and diclofenac group at both 4 weeks and 3 months of follow-up (4 weeks: VAS $4.46 \pm 1.58$ vs $5.08 \pm 1.50$, ODI $20.32 \pm 9.64$ vs $24.35 \pm 7.95 ; 3$ months: VAS $3.70 \pm 1.74$ vs $4.51 \pm 1.67$, ODI $16.67 \pm 9.04$ vs $21.18 \pm 9.56 ; P<0.05$ for all). Moreover, the proportion of patients with a significant change in LBP scales was higher in the calcitonin group (4 weeks: VAS $50.00 \%$ vs $23.40 \%$, ODI $54.83 \%$ vs $25.53 \%$; 3 months: VAS $58.06 \%$ vs $38.29 \%$, ODI $59.67 \%$ vs $38.29 \% ; P<0.05$ for all). According to MRI, $43.54 \%$ patients in the calcitonin group showed improvement compared with $21.27 \%$ patients in the diclofenac group $(P<0.05)$. Conclusion: There was greater short-term efficacy of calcitonin compared with diclofenac in patients with LBP and MC1 on MRI.

Keywords: calcitonin, diclofenac sodium, Modic changes, bone marrow lesions, low back pain

\section{Introduction}

Low back pain (LBP) is the world's most disabling condition with enormous impact on population health and social economy. ${ }^{1}$ It is estimated that LBP in less than $15 \%$ of individuals could be attributed to a specific cause. ${ }^{2}$ Hence, the vast majority of LBP patients are categorized as having nonspecific LBP. ${ }^{3}$ Many therapeutic options have been used for LBP. ${ }^{4}$ Nonsteroidal anti-inflammatory drugs (NSAIDs), especially diclofenac sodium, are widely prescribed by physicians in treating nonspecific LBP.

Although LBP may originate from many spinal structures, there is a positive association between Modic changes (MC) presented as vertebral bone marrow lesions (BMLs) 
on magnetic resonance imaging (MRI) and LBP. ${ }^{5}$ Three types of $\mathrm{MC}$ have been described according to their appearance on T1-weighted imaging (T1WI) and T2-weighted imaging (T2WI). Type I Modic changes (MC1; hypointensity on T1WI and hyperintensity on T2WI) represent disrupted and fissured endplates and vascular granulation tissue adjacent to the endplates, which correspond to vertebral body lesions; type II MC (MC2; hyperintensity on both T1WI and T2WI) indicate fatty replacements of the red bone marrow; and type III MC (MC3; hypointensity on both T1WI and T2WI) are thought to represent subchondral bone sclerosis. ${ }^{6-8}$ Generally, MC1 have been mostly reported as being associated with LBP than other MC types. Besides, the existence of the MC1 manifestation is related to persistence of symptoms. ${ }^{9-12}$ A recent histomorphometric analysis of biopsies showed that MC1 had a highest bone turnover, whereas MC2 manifested as a reduced remodeling state and $\mathrm{MC} 3$ tended to be a stable sclerotic phase, revealing the characteristics of three $\mathrm{MC}$ types through microarchitecture. ${ }^{13}$

Calcitonin is an effective inhibitor of osteoclastic bone resorption and has been approved for the treatment of osteoporosis and other conditions involving accelerated bone turnover. ${ }^{14,15} \mathrm{~A}$ few studies have demonstrated that calcitonin could reduce duration and shorten mean clinical recovery of hip BMLs, ${ }^{16-18}$ but calcitonin in the treatment of MC1, which presented as vertebral BMLs on MRI, has not been reported. Because of the antiresorptive effects of calcitonin and the state of high turnover in $\mathrm{MC1}$, we treated patients with nonspecific LBP coupled with $\mathrm{MC} 1$ by using calcitonin in recent years. If calcitonin could take effect for patients with nonspecifc LBP and $\mathrm{MC1}$, it may be demonstrated by LBP scales and imaging data. This retrospective observational study was conducted to examine the effect of calcitonin in the treatment of LBP and MC1 on MRI compared with diclofenac sodium.

\section{Patients and methods}

\section{Patients}

A total of 133 consecutive patients who were diagnosed with chronic nonspecific LBP and MC1 between October 2013 and March 2016 in our hospital were reviewed retrospectively. The definition of LBP is pain and discomfort, localized below the costal margin and above the inferior gluteal folds, with or without leg pain. ${ }^{4}$

Patients with the following characteristics were included: 1) suffered from LBP more than 3 months and 2) MC1 confirmed by lumbar MRI. Patients with the following characteristics were excluded: 1) osteoporosis, fracture, tumor, infection, structural deformity or compression of the nerve root $(\mathrm{n}=7)$; 2) rheumatic or rheumatoid arthritis disease or other serious systemic diseases $(n=1) ; 3)$ prior surgery of lumbar spine $(\mathrm{n}=1)$; and 4 ) lack of adequate follow-up data $(n=15)$. Finally, 109 patients were included in this study.

\section{Approval and consent}

The study was approved by the Medical Ethics Committee of Tianjin Medical University General Hospital and conducted in accordance with the ethical standards of the Declaration of Helsinki. Written informed consent was obtained from each subject. Owing to off-label drug use in patients, patients treated by calcitonin provided additional written informed consent for off-label use of calcitonin. Individuals who refused calcitonin were treated with diclofenac sodium.

\section{Treatment}

We conducted a retrospective study for these 109 patients. A total of 62 patients received calcitonin (Miacalcic $\AA$; Novartis Pharma Schweiz AG, Rotkreuz, Switzerland), and 47 patients who refused off-label drug received diclofenac sodium (Votalin $\AA$; Novartis Pharma Schweiz AG). All patients' baseline information, including age, sex, smoking, body mass index (BMI), imaging data, as well as intensity and duration of LBP, was gathered from chart review. Patients' data for each follow-up were also collected.

Calcitonin (50 IU) was injected intramuscularly once daily, whereas diclofenac (75 mg) was orally administered once daily for 4 weeks for the treatment of LBP associated with $\mathrm{MC1}$ on MRI. None of patients received calcium or vitamin D supplements. At the end of treatment, patients were followed up and asked about adverse effects. Meanwhile, patients were asked to do a lumbar MRI at 3 months of follow-up. Because of the correlation between MC1 and LBP, non-MC1 was considered as an obvious improvement according to MRI.

\section{Assessment of low back pain}

A visual analog scale (VAS) ranging from 0 to 10 was used to estimate LBP perception. ${ }^{19} 0$ indicates no pain at all and 10 indicates the most severe pain (intolerable pain). Oswestry Disability Index (ODI) ranging from 0 to 100 is a self-report questionnaire consisting of 10 domains, namely pain intensity, personal care, lifting, walking, sitting, standing, sleeping, sex life, social life, and traveling. The sum of the section scores ( $0-5$ for each section) was divided by the total score (50 if all sections were completed), and the resulting total was multiplied by 100 to yield a percentage score. It was used to evaluate the degree of disability before and after the therapy. ${ }^{20}$ VAS and ODI questionnaires were 
also acquired from clinical records. At least 30\% reduction in LBP scale scores (VAS and ODI) was considered as a remarkable improvement. ${ }^{21}$

\section{Analysis of imaging data}

All of the imaging data were collected and reviewed by two orthopedic surgeons (YX and JZ). Regular meetings and discussions were held to guarantee data reliability. According to the criteria presented by Modic et al, MC1 (low signal on T1WI and high signal on T2WI) were identified. Patients with a specific cause as noted earlier would be excluded in order to make sure to conform to the nature of nonspecific LBP. A patient with $\mathrm{MC1}$ is illustrated in Figure 1A and B. In addition, routine dual-energy X-ray absorptiometry scan (SONOST-3000; OsteoSys Co Ltd, Seoul, Korea) was used to evaluate bone marrow density (BMD) at L2-L4 before treatment for excluding osteoporosis.

\section{Sample size}

Based on previous study and preexperiment, we assumed a normal distribution and a VAS SD of 2.5. With a two-sided $\alpha=0.05$, a sample size of 44 patients in each group would give us a power of 0.8 to detect a mean difference of 1.5 in VAS.

\section{Statistical analysis}

Baseline characteristics were presented as mean values (with SD), frequencies (with proportions), or median values (with interquartile range). Differences between groups were assessed by the chi-squared test for categorical variables and by the independent sample $t$-test for continuous variables, whereas a paired $t$-test was performed to analyze intragroup differences. Treatment effects at 4 weeks and 3 months were also analyzed by comparing the change in the outcomes of the two groups through using independent sample $t$-test. Statistical significance was accepted for a $P$-value $<0.05$. Analyses were performed using SPSS Statistics for Windows, Version 21.0 (IBM Corp, Armonk, NY, USA).

\section{Results}

\section{Characteristics of the study population}

A total of 109 patients were included in the study (60 men and 49 women) with a mean \pm SD age of $52.88 \pm 6.26$ years. Baseline comparison of calcitonin and diclofenac groups showed that age, sex distribution, smoking, BMI, BMD, duration of LBP, as well as the scales of VAS and ODI were similar between the treatment groups $(P>0.05)$ (Table 1).

\section{Treatment effect on study parameters}

At 4 weeks and 3 months of follow-up, significant improvements were found in VAS and ODI compared with baseline in both groups. When we compared variables between the treatment groups, calcitonin group showed a significant difference in VAS and ODI $(P<0.05)$. Meanwhile, betweengroup differences in change of the outcome demonstrated that calcitonin had significant improvements in VAS and ODI compared with diclofenac sodium (Table 2). Besides, the proportion of individuals with a significant change ( $30 \%$ reduction compared to baseline) in LBP scales was higher significantly among calcitonin users than among subjects treated with diclofenac: 4 weeks: VAS $31 / 62$ vs $11 / 47$, ODI $34 / 62$ vs $12 / 47 ; 3$ months: VAS $36 / 62$ vs $18 / 47$, ODI $37 / 62$ vs $18 / 47, P<0.05$ for all (Table 3 ).
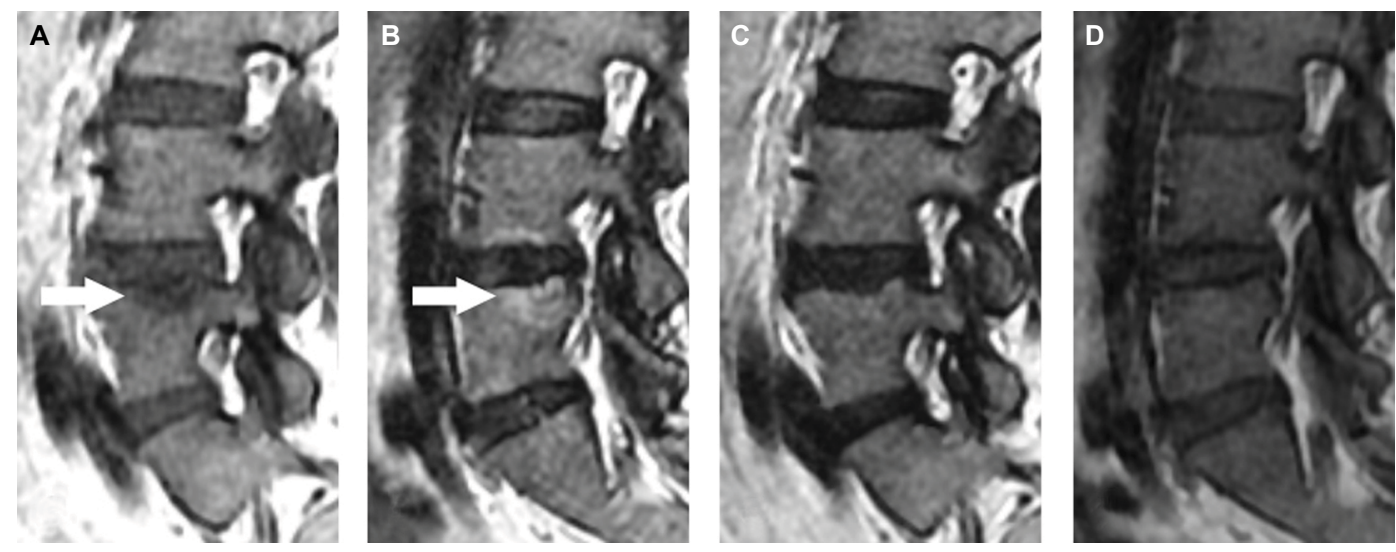

Figure I A patient with $\mathrm{MCl}$ (arrows) on MRI: low intensity on TI-weighted image (A) and high intensity on T2-weighted image (B). After calcitonin treatment, no abnormal signal intensity was found on TI- and T2-weighted images (C, D).

Abbreviations: $\mathrm{MCl}$, type I Modic changes; MRI, magnetic resonance imaging. 
Table I Baseline characteristics of patients

\begin{tabular}{|c|c|c|c|}
\hline Characteristics & Calcitonin $(n=62)$ & Diclofenac $(n=47)$ & $P$-value \\
\hline Age, mean (years) (SD) & $53.53(5.89)$ & $52.04(6.68)$ & 0.220 \\
\hline Sex, n (male) (\%) & $32(5 I .6 I)$ & $28(59.57)$ & 0.408 \\
\hline Smokers, n (\%) & $13(20.96)$ & $12(25.53)$ & 0.575 \\
\hline BMI, mean $\left(\mathrm{kg} / \mathrm{m}^{2}\right)(\mathrm{SD})$ & $24.82(2.09)$ & $24.11(2.29)$ & 0.095 \\
\hline BMD, mean $\left(\mathrm{g} / \mathrm{cm}^{2}\right)(\mathrm{SD})$ & $1.08(0.13)$ & $1.06(0.09)$ & 0.388 \\
\hline Duration, mean (days) (IQR) & $342(180,360)$ & $301(150,360)$ & 0.396 \\
\hline VAS, mean (SD) & $6.25(1.47)$ & $6.34(1.35)$ & 0.765 \\
\hline ODI, mean (SD) & 30.49 (1 I.09) & $29.74(8.73)$ & 0.703 \\
\hline
\end{tabular}

Abbreviations: BMI, body mass index; BMD, bone mineral density; IQR, interquartile range; VAS, visual analog scale; ODI, Oswestry Disability Index.

Table 2 VAS and ODI changes in the study population

\begin{tabular}{|c|c|c|c|c|c|c|}
\hline \multirow[t]{2}{*}{ Scales } & \multicolumn{3}{|c|}{ Original values } & \multicolumn{3}{|l|}{ Changes } \\
\hline & $\begin{array}{l}\text { Calcitonin } \\
(n=62)\end{array}$ & $\begin{array}{l}\text { Diclofenac } \\
(n=47)\end{array}$ & $P$-value & $\begin{array}{l}\text { Calcitonin } \\
(n=62)\end{array}$ & $\begin{array}{l}\text { Diclofenac } \\
(n=47)\end{array}$ & $P$-value \\
\hline \multicolumn{7}{|c|}{ VAS, mean (SD) } \\
\hline Baseline & $6.25(1.47)$ & $6.34(1.35)$ & 0.765 & & & \\
\hline 4 weeks & $4.46(1.58)^{*}$ & $5.08(1.50)^{*}$ & 0.042 & $\mathrm{I} .79(\mathrm{I} .46)$ & $1.25(1.20)$ & 0.044 \\
\hline 3 months & $3.70(1.74)^{*}$ & $4.51(1.67)^{*}$ & 0.018 & $2.54(1.78)$ & $1.82(1.44)$ & 0.023 \\
\hline \multicolumn{7}{|c|}{ ODI, mean (SD) } \\
\hline Baseline & 30.49 (1 1.09) & $29.74(8.73)$ & 0.703 & & & \\
\hline 4 weeks & $20.32(9.64)^{*}$ & $24.35(7.95)^{*}$ & 0.022 & $10.17(10.04)$ & $5.39(7.89)$ & 0.008 \\
\hline 3 months & $16.67(9.04)^{*}$ & $21.18(9.56)^{*}$ & 0.013 & I3.82 (II.75) & $8.56(9.26)$ & 0.010 \\
\hline
\end{tabular}

Note: $* P<0.05$ vs baseline

Abbreviations: VAS, visual analog scale; ODI, Oswestry Disability Index.

Table 3 Percentage of patients with 30\% reduction in low back pain scales at each follow-up compared with baseline

\begin{tabular}{llll}
\hline & $\begin{array}{l}\text { Calcitonin } \\
(\mathbf{n = 6 2})\end{array}$ & $\begin{array}{l}\text { Diclofenac } \\
(\mathbf{n = 4 7 )}\end{array}$ & P-value \\
\hline VAS & & & \\
4 weeks & $50.00 \%$ & $23.40 \%$ & 0.005 \\
3 months & $58.06 \%$ & $38.29 \%$ & 0.041 \\
ODI & & & \\
4 weeks & $54.83 \%$ & $25.53 \%$ & 0.002 \\
3 months & $59.67 \%$ & $38.29 \%$ & 0.027 \\
\hline
\end{tabular}

Abbreviations: VAS, visual analog scale; ODI, Oswestry Disability Index.

\section{Treatment effect on imaging data}

At 3 months of follow-up, all patients received a lumbar MRI in our hospital. In the calcitonin group, 11 patients demonstrated no MC (Figure 1), 16 patients demonstrated MC2 (Figure 2), and 35 patients demonstrated MC1 on MRI. Whereas in the diclofenac group, 4 patients did not demonstrate $\mathrm{MC}, 6$ patients demonstrated MC2, and 37 patients demonstrated MC1 on MRI. No MC3 was found in all these patients. Briefly, the proportion of patients with non-MC1, a significant improvement on MRI, was $43.54 \%$ and $21.27 \%$ in the calcitonin group and diclofenac group, respectively, $(P=0.015)$.

\section{Adverse events}

Adverse events occurred in 17/62 patients in the calcitonin group (27.41\%) and 7/47 (14.89\%) in the diclofenac group, a difference that was not significant $(P=0.118)$. Adverse effects in the calcitonin group were nausea $(3 ; 4.83 \%)$, abdominal pain $(5 ; 8.06 \%)$, diarrhea $(3 ; 4.83 \%)$, hypodynamia $(4 ; 6.45 \%)$, headache $(2 ; 3.22 \%)$, hot flushes (4; $6.45 \%)$, dizziness $(2 ; 3.22 \%)$, and hypocalcemia $(1 ; 1.61 \%)$. Adverse effects in the diclofenac group were nausea (1; $2.12 \%$ ), abdominal pain $(2 ; 4.25 \%)$, diarrhea $(2 ; 4.25 \%)$, constipation $(1 ; 2.12 \%)$, hypodynamia $(1 ; 2.12 \%)$, headache $(1 ; 2.12 \%)$, and dizziness $(2 ; 2.12 \%)$.

\section{Discussion}

In this retrospective study, we observed that calcitonin 50 IU injected intramuscularly once daily was associated with superior improvement inn patients suffering from LBP and MC1 on MRI compared with diclofenac $75 \mathrm{mg}$ once per day. Patients treated with calcitonin for 4 weeks showed a more obvious reduction in pain scores as well as disability index, as shown in VAS and ODI, compared with the patients administrated with diclofenac. In addition to the numerical change, the proportion of cases who achieved the clinically 

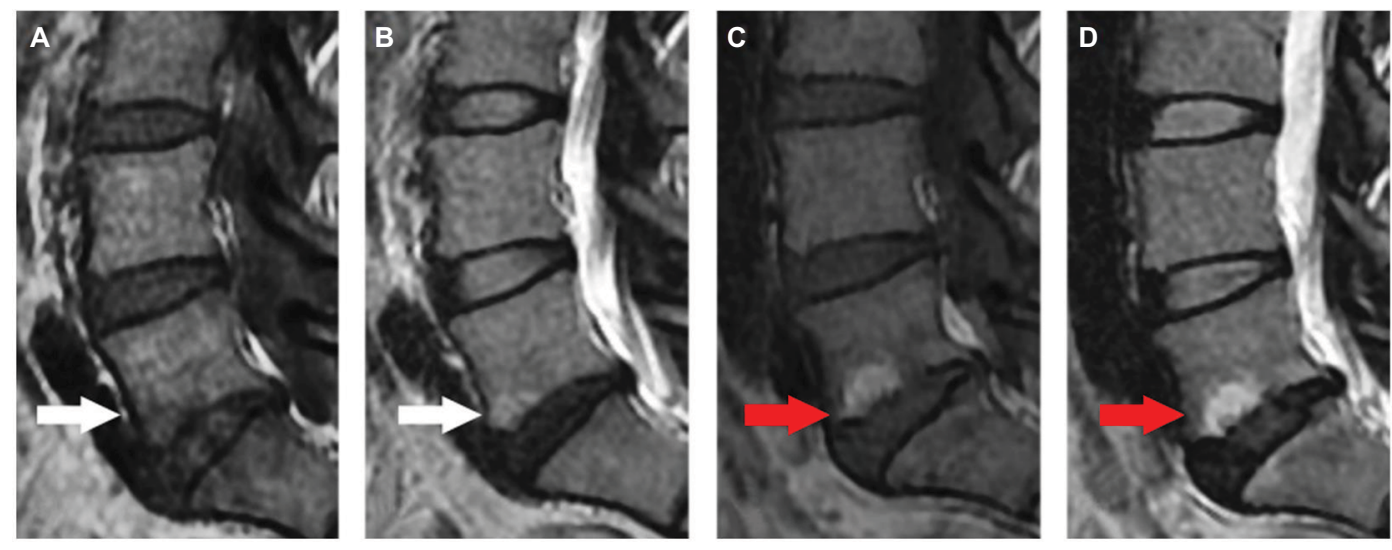

Figure 2 A patient with $\mathrm{MCl}$ (white arrows) on MRI: low intensity on TI-weighted image (A) and high intensity on T2-weighted image (B). After calcitonin treatment, $\mathrm{MCl}$ converted to MC2 (high signal intensity on TI- and T2-weighted images) (red arrows) (C, D).

Abbreviations: $\mathrm{MCl}$, type I Modic changes; MRI, magnetic resonance imaging; MC2, type II Modic changes.

meaningful improvement (30\% reduction compared with baseline) in VAS and ODI was also greater in the group of patients treated with calcitonin. Besides, the proportion of patients with significant improvement on MRI was greater in the calcitonin group than in the diclofenac group.

LBP is the major cause of disability-adjusted life years both in developed and developing countries with considerable socioeconomic impact. ${ }^{1,22,23}$ Although there is little scientific evidence on the prevalence of chronic nonspecific LBP, best estimation suggests that the prevalence is $23 \%$ or so. ${ }^{24} \mathrm{~A}$ few therapies are recommended for the management of chronic nonspecific LBP, such as exercise therapy, behavioral treatment, brief educational interventions, and pharmacological approaches including but not limited to NSAIDs and weak opioids. Although an increasing number of studies have focused on LBP with MC, few therapeutic options have been evaluated for it.

Calcitonin is a naturally occurring peptide that inhibits osteoclast function potently through specific receptors. ${ }^{25}$ Following its discovery in $1962,{ }^{26}$ an injectable form of calcitonin was introduced in the European market in 1973. The antiresorptive action of calcitonin has led to its widespread application in treating metabolic bone diseases characterized by high turnover, such as postmenopausal osteoporosis and Paget's disease of the bone. It was also applied to treat hip BMLs by a few scholars. ${ }^{16-18}$ A localized high turnover in BMLs has been verified, ${ }^{27,28}$ which may explain the positive effects of antiresorptive drugs like calcitonin on the condition extension and symptoms associated with the lesion. ${ }^{29}$ Recently, a quantitative histomorphometric study on bone biopsies found that $\mathrm{MC} 1$ presented the highest bone turnover. ${ }^{13}$ In a similar way, the role of calcitonin in inhibiting bone turnover may explain our result that calcitonin could provide a better effect in patients with LBP and MC1.

The microfractures and fissures in the endplates were identified as a major source of MC through the biomechanical mechanism. As mentioned earlier, $\mathrm{MC} 1$ are disruption and fissuring of the endplates..$^{30}$ If microfractures have taken place recently, phenomenon that decreases signal intensity on T1WI and increased signal intensity on T2WI will be found, which is equivalent to $\mathrm{MC} 1 .^{31}$ Therefore, this appearance might reflect edema and inflammatory response following accumulated lesions. Moreover, the high turnover state in $\mathrm{MC} 1$ may be caused by the microfractures in endplates under the condition of persistent inflammatory stimulus. ${ }^{32}$ Calcitonin has been found to promote the cartilaginous phase of fracture healing in animal studies. These studies concluded that calcitonin facilitates early endochondral ossification, leading to enhanced chondrification and earlier maturation of callus. In a randomized controlled trial on calcitonin in elderly patients with hip fracture, no significant difference was found in functional recovery, length of hospital stay, or complications between calcitonin group and placebo group. However, a higher rate of fracture fusion and a tendency of diminishing bone loss and pain were observed in calcitonin group. ${ }^{33}$ Accordingly, the microfractures in $\mathrm{MC} 1$ may gain an accelerated healing from calcitonin. Besides, the pharmacologic effect of calcitonin in maintaining subchondral and trabecular microstructure has been reported both in animal experiments and clinical trials, ${ }^{34-37}$ which could contribute to improving the biomechanical characteristics of the healing bone, such as fracture load and stiffness.

In addition to inhibition of bone turnover, acceleration of bone healing, and protection of bone microstructure, 
calcitonin has been shown to have a direct positive effect on pain reduction, and thus is clinically useful in several diseases that involve bone pain, such as pain owing to bone metastasis. The mechanism for the analgesic effect of calcitonin is yet to be studied in details. In humans, similarities were found between calcitonin- and morphine-induced analgesia, ${ }^{38,39}$ and elevation of plasma $\beta$-endorphin level following administration of calcitonin was reported, ${ }^{40-42}$ suggesting that endogenous opiate system may be involved in the mediation of analgesic role triggered by calcitonin. Besides, there is sufficient evidence that calcitonin has a direct effect on the central nervous system (CNS). Specific calcitonin receptors have been found in areas of the CNS involved in pain perception as well as transmission and modulation of sensory stimuli. ${ }^{43,44}$

Since MC1 have been more frequently reported as being associated with LBP and it correlates to persistence of LBP symptoms, ${ }^{9-12}$ we defined non-MC1 which indicating improved significantly on MRI. In our study, the proportions of patients with non-MC1 after treatment were $43.54 \%$ and $21.27 \%$ in the two groups, showing an obvious improvement in calcitonin group in the light of MRI.

As an anti-osteoporosis drug, calcitonin could relieve pain originating from osteoporotic vertebral compression fracture. ${ }^{45}$ In this retrospective study, patients underwent dual-energy X-ray absorptiometry scan before treatment for excluding osteoporosis, showing its effective role in patients with nonspecific LBP and MC1. Koivisto et al reported that zoledronic acid had a positive efficacy in the treatment of LBP with MC, with mild to moderate side effects. ${ }^{46}$ But due to the risk of developing kidney failure, renal function must be monitored during zoledronic acid treatment. Hence, we think that calcitonin may be more secure in treating LBP with MC1. Besides, calcitonin has the analgesic effect that is lacking in other anti-osteoporosis drugs.

NSAIDs are the most frequently prescribed medications around the world and are recommended for short-term use in patients with chronic LBP in order to relieve pain. ${ }^{24}$ In our study, we found that calcitonin could offer more effects compared with diclofenac in the treatment of chronic nonspecific LBP with MC1 on MRI, which manifested as more obvious reduction in VAS and ODI, as well as a much higher proportion of significantly improved patients. Meanwhile, side effect was not significantly different in the calcitonin group compared with the diclofenac group, although the incidence was higher in the calcitonin group.

This study has some limitations that must be pointed out. The current study was a single-center retrospective observational study that lacked randomization, which may induce a potential bias. In addition, many factors could take part in the development and prognosis of LBP due to its multidimensional nature. The potential influence of physical exercise, education, and psychosocial factors was not taken into account in our study. Lack of long-term follow-up was also a limitation in our study. Further multi-center randomized control trial with long-term follow-up is needed to evaluate the therapeutic use of calcitonin for the treatment of LBP accompanied by MC1.

\section{Conclusion}

In this retrospective comparative study, patients with LBP associated with MC1 on MRI who were treated with calcitonin showed statistically significant improvements compared to the diclofenac group in all measured parameters. As far as we know, this is first study to evaluate the effect of calcitonin on LBP with MC1. Although there is still a controversy regarding association between $\mathrm{MC}$ and LBP, our findings in this study could make a recommendation that calcitonin is a treatment protocol for patients with nonspecific LBP and MC1 when all other treatment approaches have failed.

\section{Author contributions}

All the authors contributed toward data analysis, drafting, and critically revising the paper; gave final approval of the version to be published; and agree to be accountable for all aspects of the work.

\section{Disclosure}

The authors report no conflicts of interest in this work.

\section{References}

1. Vos T, Flaxman AD, Naghavi M, et al. Years lived with disability (YLDs) for 1160 sequelae of 289 diseases and injuries 1990-2010: a systematic analysis for the Global Burden of Disease Study 2010. Lancet. 2012;380(9859):2163-2196.

2. Scientific approach to the assessment and management of activityrelated spinal disorders. A monograph for clinicians. Report of the Quebec Task Force on Spinal Disorders. Spine (Phila Pa 1976). 1987;12(7 Suppl):S1-S59.

3. Deyo RA, Weinstein JN. Low back pain. N Engl J Med. 2001;344(5): 363-370.

4. Burton AK, Balagué F, Cardon G, et al; COST B13 Working Group on Guidelines for Prevention in Low Back Pain. Chapter 2. European guidelines for prevention in low back pain: November 2004. Eur Spine J. 2006;15(Suppl 2):S136-S168.

5. Thompson KJ, Dagher AP, Eckel TS, Clark M, Reinig JW. Modic changes on MR images as studied with provocative diskography: clinical relevance: a retrospective study of 2457 disks. Radiology. 2009;250(3):849-855.

6. Albert HB, Briggs AM, Kent P, Byrhagen A, Hansen C, Kjaergaard $\mathrm{K}$. The prevalence of MRI-defined spinal pathoanatomies and their association with modic changes in individuals seeking care for low back pain. Eur Spine J. 2011;20(8):1355-1362. 
7. Jensen TS, Bendix T, Sorensen JS, Manniche C, Korsholm L, Kjaer P. Characteristics and natural course of vertebral endplate signal (Modic) changes in the Danish general population. BMC Musculoskelet Disord. 2009; $10: 81$.

8. Jensen TS, Kjaer P, Korsholm L, et al. Predictors of new vertebral endplate signal (Modic) changes in the general population. Eur Spine J. 2010;19(1):129-135.

9. Kääpä E, Luoma K, Pitkäniemi J, Kerttula L, Grönblad M. Correlation of size and type of modic types 1 and 2 lesions with clinical symptoms: a descriptive study in a subgroup of patients with chronic low back pain on the basis of a university hospital patient sample. Spine (Phila Pa 1976). 2012;37(2):134-139.

10. Kuisma M, Karppinen J, Niinimaki J, et al. Modic changes in endplates of lumbar vertebral bodies: prevalence and association with low back and sciatic pain among middle-aged male workers. Spine (Phila Pa 1976). 2007;32(10):1116-1122.

11. Mitra D, Cassar-Pullicino VN, McCall IW. Longitudinal study of vertebral type-1 end-plate changes on MR of the lumbar spine. Eur Radiol. 2004;14(9):1574-1581.

12. Toyone T, Takahashi K, Kitahara H, Yamagata M, Murakami M, Moriya $\mathrm{H}$. Vertebral bone-marrow changes in degenerative lumbar disc disease. An MRI study of 74 patients with low back pain. J Bone Joint Surg Br. 1994;76(5):757-764.

13. Perilli E, Parkinson IH, Truong LH, Chong KC, Fazzalari NL, Osti OL. Modic (endplate) changes in the lumbar spine: bone micro-architecture and remodelling. Eur Spine. 2015;24(9):1926-1934.

14. Chesnut $\mathrm{CH}$ 3rd, Silverman S, Andriano K, et al. A randomized trial of nasal spray salmon calcitonin in postmenopausal women with established osteoporosis: the prevent recurrence of osteoporotic fractures study. PROOF Study Group. Am J Med. 2000;109(4):267-276.

15. Karsdal MA, Henriksen K, Arnold M, Christiansen C. Calcitonin: a drug of the past or for the future? Physiologic inhibition of bone resorption while sustaining osteoclast numbers improves bone quality. BioDrugs. 2008;22(3):137-144.

16. Arayssi TK, Tawbi HA, Usta IM, Hourani MH. Calcitonin in the treatment of transient osteoporosis of the hip. Semin Arthritis Rheum. 2003;32(6):388-397.

17. Laktasic-Zerjavic N, Curkovic B, Babic-Naglic D, Potocki K, Prutki M, Soldo-Juresa D. [Transient osteoporosis of the hip in pregnancy. Successful treatment with calcitonin: a case report]. $Z$ Rheumatol. 2007;66(6):510-513 German.

18. Varenna M, Sinigaglia L, Binelli L, Beltrametti P, Gallazzi M. Transient osteoporosis of the hip: a densitometric study. Clin Rheumatol. 1996;15(2):169-173.

19. Scott PJ, Huskisson EC. Measurement of functional capacity with visual analogue scales. Rheumatol Rehabil. 1977;16(4):257-259.

20. Fairbank JC, Couper J, Davies JB, O’Brien JP. The Oswestry low back pain disability questionnaire. Physiotherapy. 1980;66(8):271-273.

21. Ostelo RW, Deyo RA, Stratford P, et al. Interpreting change scores for pain and functional status in low back pain: towards international consensus regarding minimal important change. Spine (Phila Pa 1976). 2008;33(1):90-94.

22. Hoy D, March L, Brooks P, et al. The global burden of low back pain: estimates from the Global Burden of Disease 2010 study. Ann Rheum Dis. 2014;73(6):968-974.

23. Global Burden of Disease Study 2013 Collaborators. Global, regional, and national incidence, prevalence, and years lived with disability for 301 acute and chronic diseases and injuries in 188 countries, 1990-2013. a systematic analysis for the Global Burden of Disease Study 2013 Lancet. 2015;386(9995):743-800.

24. Airaksinen O, Brox JI, Cedraschi C, et al; COST B13 Working Group on Guidelines for Chronic Low Back Pain. Chapter 4. European guidelines for the management of chronic nonspecific low back pain. Eur Spine J. 2006;15(Suppl 2):S192-S300.
25. Muñoz-Torres M, Alonso G, Raya MP. Calcitonin therapy in osteoporosis. Treat Endocrinol. 2004;3(2):117-132.

26. Copp DH, Cheney B. Calcitonin-a hormone from the parathyroid which lowers the calcium-level of the blood. Nature. 1962;193:381-382.

27. McCarthy EF. The pathology of transient regional osteoporosis. Iowa Orthop J. 1998;18:35-42.

28. Berger CE, Kröner AH, Minai-Pour MB, Ogris E, Engel A. Biochemical markers of bone metabolism in bone marrow edema syndrome of the hip. Bone. 2003;33(3):346-351.

29. Eriksen EF, Ringe JD. Bone marrow lesions: a universal bone response to injury? Rheumatol Int. 2012;32(3):575-584.

30. Modic MT, Steinberg PM, Ross JS, Masaryk TJ, Carter JR. Degenerative disk disease: assessment of changes in vertebral body marrow with MR imaging. Radiology. 1988;166(1 Pt 1):193-199.

31. Hansson T, Roos B. Microcalluses of the trabeculae in lumbar vertebrae and their relation to the bone mineral content. Spine (Phila Pa 1976). 1981;6(4):375-380.

32. Dudli S, Fields AJ, Samartzis D, Karppinen J, Lotz JC. Pathobiology of Modic changes. Eur Spine J. 2016;25(11):3723-3734.

33. Huusko TM, Karppi P, Kautiainen H, Suominen H, Avikainen V, Sulkava R. Randomized, double-blind, clinically controlled trial of intranasal calcitonin treatment in patients with hip fracture. Calcif Tissue Int. 2002;71(6):478-484.

34. Chesnut $\mathrm{CH}$ 3rd, Majumdar S, Newitt DC, et al. Effects of salmon calcitonin on trabecular microarchitecture as determined by magnetic resonance imaging: results from the QUEST study. J Bone Miner Res. 2005;20(9):1548-1561.

35. Rizzoli R, Sigaud A, Azria M, Herrmann FR. Nasal salmon calcitonin blunts bone microstructure alterations in healthy postmenopausal women. Osteoporos Int. 2015;26(1):383-393.

36. Bulbul M, Esenyel CZ, Esenyel M, Ayanoglu S, Bilgic B, Gulmez T. Effects of calcitonin on the biomechanics, histopathology, and radiography of callus formation in rats. J Orthop Sci. 2008;13(2):136-144.

37. Li X, Luo X, Yu N, Zeng B. Effects of salmon calcitonin on fracture healing in ovariectomized rats. Saudi Med J. 2007;28(1):60-64.

38. Martín MI, Goicoechea C, Colado MI, Alfaro MJ. Analgesic effect of salmon-calcitonin administered by two routes. Effect on morphine analgesia. Eur J Pharmacol. 1992;224(1):77-82.

39. Miralles FS, Lopez-Soriano F, Puig MM, Perez D, Lopez-Rodriguez F. Postoperative analgesia induced by subarachnoid lidocaine plus calcitonin. Anesth Analg. 1987;66(7):615-618.

40. Rohner J, Planche D. Mechanism of the analgesic effect of calcitonin evidence for a twofold effect: morphine-like and cortisone-like. Clin Rheumatol. 1985;4(2):218-219.

41. Franceschini R, Cataldi A, Barreca T, Salvemini M, Rolandi E. Plasma beta-endorphin, ACTH and cortisol secretion in man after nasal spray administration of calcitonin. Eur J Clin Pharmacol. 1989;37(4):341-343.

42. Laurian L, Oberman Z, Graf E, Gilad S, Hoerer E, Simantov R. Calcitonin induced increase in ACTH, beta-endorphin and cortisol secretion. Horm Metab Res. 1986;18(4):268-271.

43. Fischer JA, Tobler PH, Kaufmann M, et al. Calcitonin: regional distribution of the hormone and its binding sites in the human brain and pituitary. Proc Natl Acad Sci U S A. 1981;78(12):7801-7805.

44. Sexton PM. Central nervous system binding sites for calcitonin and calcitonin gene-related peptide. Mol Neurobiol. 1991;5(2-4):251-273.

45. Knopp JA, Diner BM, Blitz M, Lyritis GP, Rowe BH. Calcitonin for treating acute pain of osteoporotic vertebral compression fractures: a systematic review of randomized, controlled trials. Osteoporos Int. 2005;16(10):1281-1290.

46. Koivisto K, Kyllönen E, Haapea M, et al. Efficacy of zoledronic acid for chronic low back pain associated with Modic changes in magnetic resonance imaging. BMC Musculoskelet Dis. 2014;15:64. 
The Journal of Pain Research is an international, peer reviewed, open access, online journal that welcomes laboratory and clinical findings in the fields of pain research and the prevention and management of pain. Original research, reviews, symposium reports, hypothesis formation and commentaries are all considered for publication.
The manuscript management system is completely online and includes a very quick and fair peer-review system, which is all easy to use. Visit http://www.dovepress.com/testimonials.php to read real quotes from published authors. 